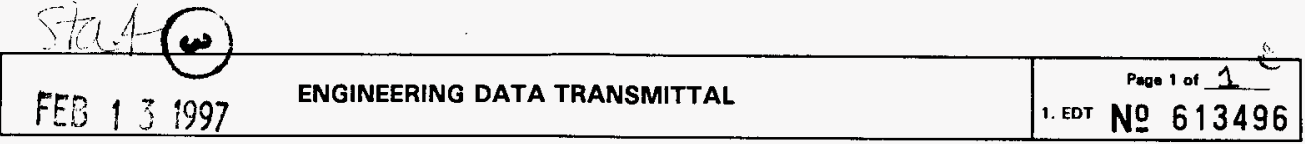

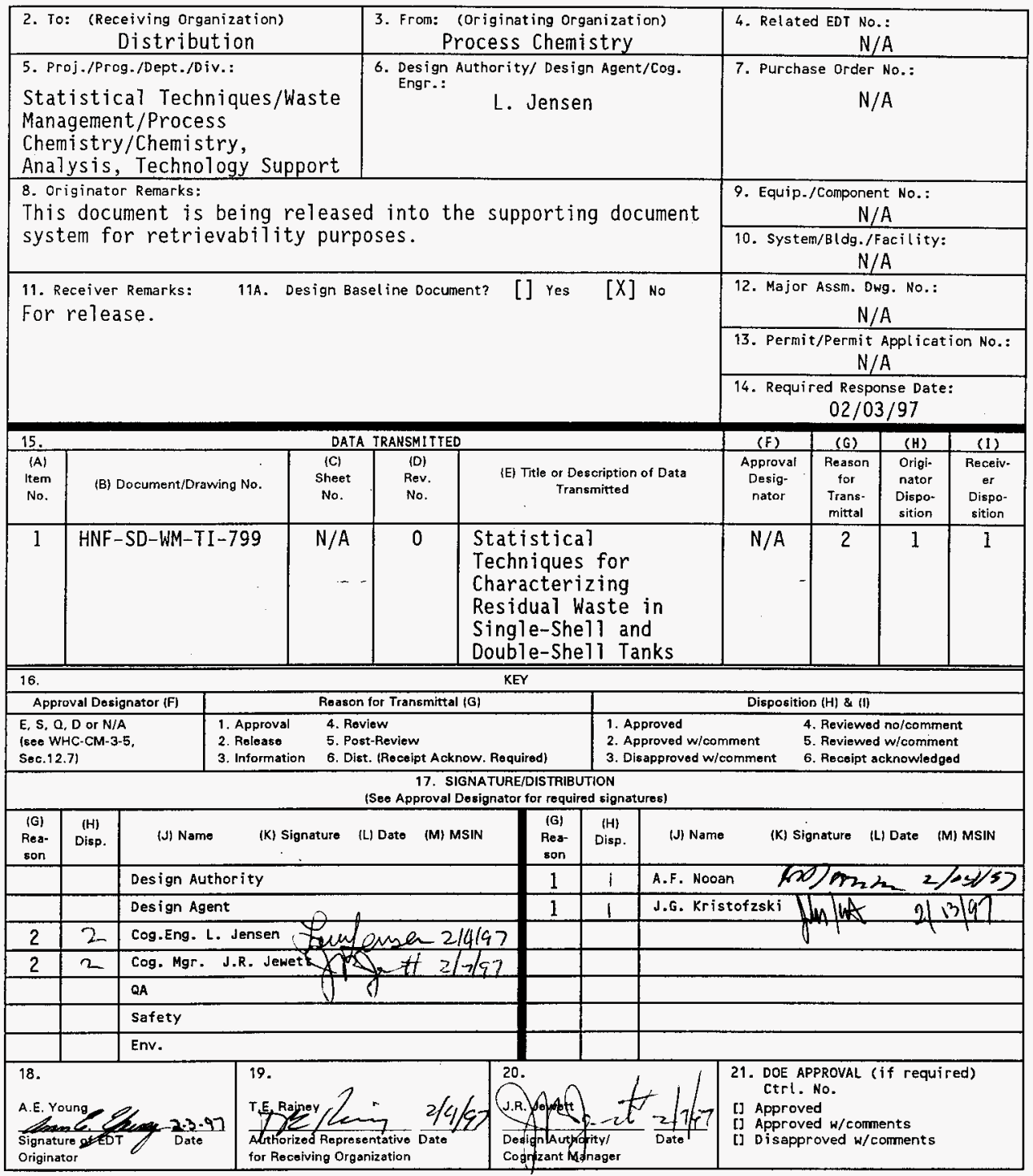

BD-7400-172-2 (05/96) GEF097 


\title{
Statistical Techniques for Characterizing Residual Waste in Single-Shell and Double-Shell Tanks
}

\author{
L. Jensen
}

Numatec Hanford Corp. . Richland. WA 99352

U.S. Department of Energy Contract DE-AC06-96RL13200

EDT/ECN: EDT-613496 UC: 2070

Org Code: 8C510 Charge Code: E20145

B\&R Code: EW 3120074 Total Pages: st

Key Words: Statistical Techniques, Characterizing Residual Waste. Residual. Waste, Single-Shell Tank. Double-Shell Tank, Vadose Zone

Abstract: N/A

TRADEMARK DISCLAIMER. Reference herein to any specific comnerciat product, process, or service by trade name, trademark, manufacturer, or otherwise, does not necessarily constitute or imply its endorsement, recommendation, or favoring by the United States Government or any agency thereof or its contractors or subcontractors.

Printed in the United States of America. To obtain copies of this document, contact: Document Control Services, P.O. Box 950, Mailstop H6-08, Richland WA 99352, Phone (509) 372-2420; Fax (509) 376-4989.

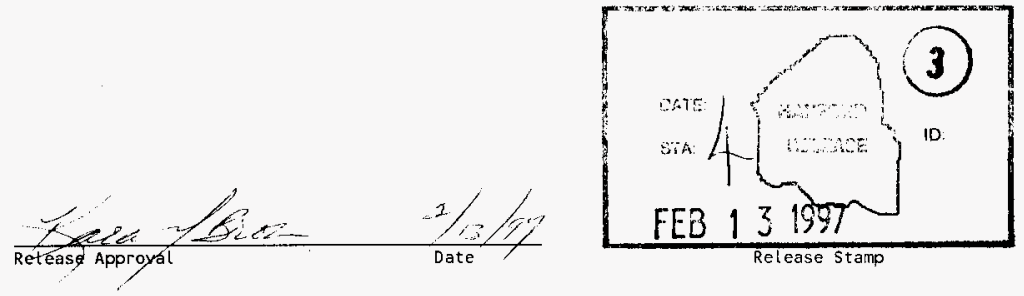

Approved for Public Release 
HNF-SD-WM-TI-799

Revision 0

\section{Statistical Techniques for Characterizing Residual Waste in Single-Shell and Double-Shell Tanks}

L. Jensen

Numatec Hanford Corporation

F. R. Reich

SGN Eurisys Services Corporation

Date Published

February 1997

Prepared for the U.S. Department of Energy

Assistant Secretary for Environmental Management

Project Hanford Mangement Contractor for the

U.S. Department of Energy under Contract DE-AC06-96RL13200

Approved for Public Release 
HNF-SD-WM-TI-799, Rev. 0

This page intentionally left blank 


\section{CONTENTS}

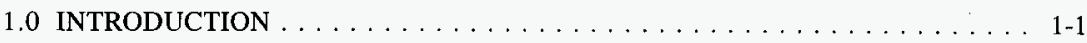

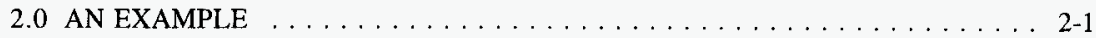

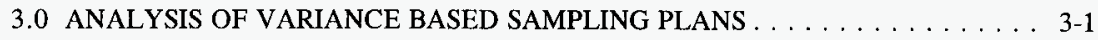

3.1 MEAN ANALYTE INVENTORY $\ldots \ldots \ldots \ldots \ldots \ldots \ldots \ldots \ldots \ldots$. $\ldots \ldots \ldots$

3.2 STATISTICAL SAMPLING PLANS $\ldots \ldots \ldots \ldots \ldots \ldots \ldots \ldots \ldots$

4.0 VARIANCE COMPONENT ANALYSIS $\ldots \ldots \ldots \ldots \ldots \ldots \ldots \ldots \ldots$ 4-1

4.1 RESIDUAL WASTE VOLUME $\ldots \ldots \ldots \ldots \ldots \ldots \ldots \ldots \ldots \ldots$ 4-1

4.2 ANALYTE CONCENTRATION $\ldots \ldots \ldots \ldots \ldots \ldots \ldots \ldots \ldots$. $\ldots \ldots$

4.3 VARIANCE OF THE MEAN $\ldots \ldots \ldots \ldots \ldots \ldots \ldots \ldots . \ldots .4$

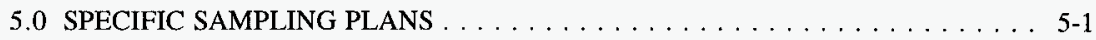

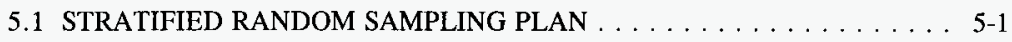

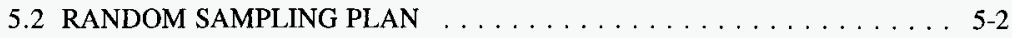

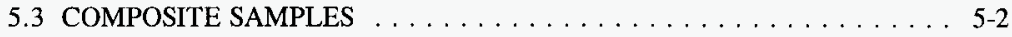

5.4 COMPARISON OF SAMPLING PLANS $\ldots \ldots \ldots \ldots \ldots \ldots$

6.0 SAMPLING PLAN FOR THE WASTE PLUME $\ldots \ldots \ldots \ldots \ldots \ldots$ 6-1

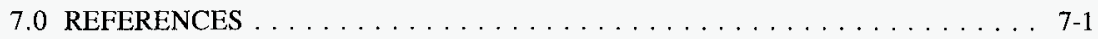

\section{APPENDICES}

A TANK AX-104 SAMPLING AND CHARACTERIZATION MODELS . . . . . . . A A-1

B TANK AX-104 CONSTRUCTION AND OPERATIONAL BACKGROUND SUMMARY $\ldots \ldots \ldots \ldots \ldots \ldots \ldots \ldots$ B-1 


\section{LIST OF FIGURES}

1 Tank AX-104 Tank Bottom Waste Depth Profile Map . . . . . . . . . . . A-7

2A Tank AX-104 Bottom Waste Depth Example Model with Depth

Contours from 8 in. to 14 in . . . . . . . . . . . . . . . . A-9

2B Tank AX-104 Bottom Waste Depth Example Model Showing Waste

Tank Area, Waste Depth and Volume Estimates . . . . . . . . . . . A A-10

3 Image of AX-104 Tank Dome Surface from Riser 3-A, Looking North . . . . . . . A-13

\section{LIST OF TABLES}

5-1 Comparison of sampling plans $\ldots \ldots \ldots \ldots \ldots \ldots \ldots \ldots \ldots \ldots \ldots$ 
HNF-SD-WM-TI-799 Rev. 0

\section{LIST OF TERMS}

ALC

ANOVA

df

DST

HTI

$\mathrm{kL}$

LL

REML

SST

UL air lift circulators

analysis of variance

degrees of freedom

Double-Shell tank

Hanford Tank Initiative

kilo-liters

low level(95\%)

restricted maximum likelihood

Single-Shell Tank

upper level( $(95 \%)$ 
HNF-SD-WM-TI-799 Rev. 0

This page intentionally left blank. 


\subsection{INTRODUCTION}

A primary objective of the Hanford Tank Initiative (HTI) project is to develop methods to estimate the inventory of residual waste in single-shell and double-shell tanks. A second objective is to develop methods to determine the boundaries of waste that may be in the waste plume in the vadose zone.

This document presents statistical sampling plans that can be used to estimate the inventory of analytes within the residual waste within a tank. Sampling plans for estimating the inventory of analytes within the waste plume in the vadose zone are also presented. Inventory estimates can be used to classify the residual waste with respect to chemical and radiological hazards. Based on these estimates, it will be possible to make decisions regarding the final disposition of the residual waste.

Four sampling plans for the residual waste in a tank are presented. The first plan is based on the assumption that, based on some physical characteristic, the residual waste can be divided into disjoint strata, and waste samples obtained from randomly selected locations within each stratum. The second plan is that waste samples are obtained from randomly selected locations within the waste. The third and fourth plans are similar to the first two, except that composite samples are formed from multiple samples. Common to the four plans is that, in the laboratory, replicate analytical measurements are obtained from homogenized waste samples.

The statistical sampling plans for the residual waste are similar to the statistical sampling plans developed for the tank waste characterization program (Jensen and Liebetrau 1988). In that program, the statistical sampling plans required multiple core samples of waste, and replicate analytical measurements from homogenized core segments.

A statistical analysis of the analytical data, obtained from use of the statistical sampling plans developed for the characterization program or from the HTI project, provide estimates of mean analyte concentrations and confidence intervals on the mean. In addition, the statistical analysis provides estimates of spatial and measurement variabilities. The magnitude of these sources of variability are used to determine how well the inventory of the analytes in the waste have been estimated.

This document provides statistical sampling plans that can be used to estimate the inventory of the analytes in the residual waste in single-shell (SST) and double-shell tanks (DST) and in the waste plume in the vadose zone. The statistical sampling plan can be used to characterize the residual waste in any tank or characterize the waste plume under any tank farm. 
HNF-SD-WM-TI-799 Rev. 0

This page intentionally left blank. 


\subsection{AN EXAMPLE}

The statistical sampling plans developed for the HTI project may require more waste samples and different types of waste samples as compared to the number of core samples required in the waste characterization program. The difference is illustrated by the number of samples that may be needed to characterize the residual waste in tank 241-AX-104. In this tank, residual waste is in the bottom of the tank, on the walls of the tank, on the interior of the tank dome, on the interior and exterior of air lift circulators and on other pipes and equipment in the tank. In addition, due to waste leaking out of some tanks, the soil in the vadose zone around this tank may contains a waste plume.

To characterize the residual waste in this tank, a statistical sampling plan is needed to characterize the residual waste in the bottom, on the walls, on the dome, on the pipes and equipment inside the tank, and in the vadose zone. In this and other empty tanks, the residual waste may be located in many places and it may have a different composition according to location. Consequently, a statistical sampling plan needs to be applied to characterize the residual waste in each location.

Appendix A contains preliminary estimates of surface areas and the volume of residual waste in the bottom of the tank, on the walls of the tank, on the interior of the tank dome, on the interior and exterior of air lift circulators and on other pipes and equipment in tank 241-AX104. The information in this appendix may be useful in developing a statistical sampling plan that can be used specifically for characterizing the residual waste in tank 241-AX-104.

Appendix B contains a description of tank 241-AX-104 based on construction records. It also contains a summary of the waste transfer history. This information may be useful in determining preliminary estimates of the composition of the residual waste. 
HNF-SD-WM-TI-799 Rev. 0

This page intentionally left blank. 


\subsection{ANALYSIS OF VARIANCE BASED SAMPLING PLANS}

The statistical sampling plans presented here are designed to estimate the mean analyte inventory in the residual waste. They are not designed to estimate extreme analyte concentrations. Mean analyte concentrations, and standard deviations of the mean, can be estimated from data obtained from relatively few samples. Large numbers of samples are required to estimate extreme concentrations. Consequently, the characterization results from waste samples obtained using these sampling plans will be in terms of mean analyte concentrations and mean inventories.

Statistical methods based on the analysis of variance (ANOVA) will be used to analyze the HTI characterization data obtained from a chemical analysis of residual waste samples. The ANOVA is used to estimate mean analyte concentrations, the variance of the mean, and confidence intervals on the mean. Consequently, the sampling plans are based on ANOVA models for the characterization data.

\subsection{MEAN ANALYTE INVENTORY}

The inventory ${ }^{1}$ of an analyte within the residual waste is

$$
\mathrm{I}=\sum_{\mathrm{i}=1}^{\mathrm{k}} \overline{\mathrm{C}}_{\mathrm{i}} \mathrm{V}_{\mathrm{i}}
$$

where $\bar{C}_{i}$ and $V_{i}$ denote the mean concentration of an analyte and the mean volume ${ }^{2}$ of the residual waste in the ith compartment. The waste compartments are the tank bottom, the walls, the dome, and the equipment inside the tank; $k$ denotes the number of compartments.

If $\mathrm{C}_{\mathrm{i}}$ and $\mathrm{V}_{\mathrm{j}}$ are uncorrelated, the variance of the inventory, $\sigma^{2}(\mathrm{I})$, is

$$
\begin{gathered}
\sigma^{2}(\mathrm{I})=\sum_{\mathrm{i}-1}^{\mathrm{k}} \sigma^{2}\left(\overline{\mathrm{C}}_{\mathrm{i}} \mathrm{V}_{\mathrm{i}}\right), \\
\sigma^{2}\left(\overline{\mathrm{C}}_{\mathrm{i}} \mathrm{V}_{\mathrm{i}}\right)=\overline{\mathrm{C}}_{\mathrm{i}}^{2} \sigma^{2}\left(\mathrm{~V}_{\mathrm{i}}\right)+\mathrm{V}_{\mathrm{i}}^{2} \sigma^{2}\left(\overline{\mathrm{C}}_{\mathrm{i}}\right)+\sigma^{2}\left(\overline{\mathrm{C}}_{\mathrm{i}}\right) \sigma^{2}\left(\mathrm{~V}_{\mathrm{i}}\right) .
\end{gathered}
$$

${ }^{1}$ If concentrations are stated on a weight basis an additional factor denoting density of the waste should be included in Equation 3.1. The density will be assumed to be a constant and can be incorporated into the mean and standard deviation by multiplication.

${ }^{2}$ The mean volume is an estimate of volume based on multiple observations. It is not necessarily an arithmetic mean. An estimate of error, similar to a standard deviation, is required. 
An estimate ${ }^{3}$ of the variance of $\mathrm{I}, \hat{\sigma}^{2}(\mathrm{I})$, is needed so that questions concerning the variability of inventory estimates can be addressed. Equation 3.2 shows that the variance of the inventory is a function of the mean analyte concentration, the variance of the mean analyte concentration, the volume estimate and the variance of the volume estimate. To address questions regarding the magnitude of the variability of the inventory, it is necessary to address questions concerning the magnitude of the variability of the mean analyte concentration and the variability of the volume estimate.

The width of a 95 percent confidence interval on the inventory is used to indicate how well the inventory has been estimated. The confidence interval on the inventory is used to determine whether the inventory of an analyte exceeds or cannot be distinguished from a "threshold" or regulatory limit. The lower and upper limits are

$$
\begin{aligned}
& \operatorname{LL}(95 \%)=I-t_{(d f, 0.025)} \sqrt{\sigma^{2}(I)} \\
& U L(95 \%)=I+t_{(d f, 0.025)} \sqrt{\sigma^{2}(I)}
\end{aligned}
$$

where $\hat{\sigma}^{2}(\mathrm{I})$ is the estimate of the variance of $I$ and $t_{(d f, 0.025)}$ is the appropriate quantile, from Student's t distribution with df degrees of freedom, for a two-sided 95 percent confidence interval.

\subsection{STATISTICAL SAMPLING PLANS}

Two distinct types of statistical sampling plans are presented. The first type of statistical plan is used for characterizing the residual waste in a SST or DST. These plans are developed in Sections 4.0 and 5.0. The second type of plan is used to locate the boundary and to characterize waste within an underground plume in the vadose zone. These sampling plans are outlined in Section 6.0.

The statistical sampling plans for characterizing the residual waste in a SST or DST are similar to the reference sampling plan (Jensen and Liebetrau 1988) developed for characterizing the waste in SSTs. The statistical plans for estimating the waste plume are similar to plans used by the mining industry to estimate the location and mineral concentration of ore bodies (Cressie 1993).

${ }^{3} \mathrm{~A}$ " $\wedge "$ is used to denote the estimate of a population parameter. 


\subsection{VARIANCE COMPONENT ANALYSIS}

To characterize the residual waste, a sampling plan is needed to characterize the waste in each compartment (the bottom, the walls, the dome, and on equipment in the tank). For a given compartment, the inventory estimate consists of two parts $\mathrm{I}=\overline{\mathrm{CV}}$ where $\overline{\mathrm{C}}$ denotes the mean analyte concentration and $\mathrm{V}$ the estimate of residual waste volume. A statistical sampling plan for estimating the mean analyte concentration in the residual waste in a SST or DST is presented in Section 4.2. Statistical sampling plans for the residual waste volume are not addressed here. However, the need for estimates of the residual waste volume is addressed in Section 4.1 .

\subsection{RESIDUAL WASTE VOLUME}

It is assumed that estimates of the waste volume, $\mathrm{V}$, and the variance of the volume, $\sigma^{2}(\mathrm{~V})$, are available for each waste compartment. The reason for estimating the variance of the residual waste volume is as follows. Let $\hat{\sigma}(V)$ be the estimated standard deviation (square root of the variance) of the volume $\mathrm{V}$ based on $\mathrm{df}$ degrees of freedom. The one-sided upper 95 percent confidence limit ${ }^{4}$ on the true unknown mean volume is

$$
\mathrm{UL}(95 \%)=\mathrm{V}+\mathrm{t}_{(\mathrm{df}, 0.05)} \sigma(\mathrm{V})
$$

where $t_{(\mathrm{df}, 0.05)}$ is the appropriate quantile, from Student's $\mathbf{t}$ distribution with df degrees of freedom, for a one-sided 95 percent confidence interval. This upper limit, UL(95\%), is used to judge whether or not the volume of residual waste remaining in the tank satisfies regulatory concerns. To compute the upper limit to the one-sided confidence interval, methods to estimate the volume, $\mathrm{V}$, the variance $\hat{\sigma}^{2}(\mathrm{~V})$, and the degrees of freedom, df, need to be developed. The methods may be qualitative. These methods are not addressed in this document. A two-sided confidence interval on the volume has a form similar to Equation 3.3.

\subsection{ANALYTE CONCENTRATION}

A statistical sampling plan for estimating the concentration of analytes in the residual waste in the tank bottom is developed in this section. The plan is designed to obtain the data needed to estimate the mean concentration, the variance of the mean concentration and confidence

${ }^{4}$ Due to the type of volume measurements that will be available, this interval may not have the usual interpretation associated with a confidence interval. 
intervals on the mean. The statistical plans for estimating the concentration of analytes in the residual waste on tank walls, dome, and internal equipment are similar.

The statistical sampling plan contains four steps:

- Divide the tank floor into disjoint strata or sectors,

- Obtain multiple waste samples within each sector,

- Prepare multiple aliquots of each sample for analysis,

- Perform multiple chemical analyses on each aliquot.

Comments on the above steps: In stratified sampling the population is divided into disjoint sub-populations. The sub-populations are called strata. For a tank, two types of stratification may be used. The first type is that the waste in the tank bottom, walls dome, and internal equipment are the strata. The second type is that, for example, the waste on the floor can be divided into strata or sectors based on some physical characteristic. In each case, the strata should be formed so that the wastes within each strata have similar properties.

To ensure that analyte concentration estimates are unbiased, the locations within each sector for obtaining samples should be randomly selected. If they are not randomly selected, concentration estimates may be biased.

It will be assumed that each sample is complete; i.e., each sample contains material from the waste surface to the waste bottom. A complete sample is not a "scraping" from the surface. Multiple aliquots of each sample are to be prepared for chemical analysis, and replicate chemical analyses performed on each aliquot.

The ANOVA model for the sampling plan, is a hierarchical or nested classification model. It is a random effects model having the form

$$
\mathrm{y}_{\mathrm{ijkm}}=\mu+\mathrm{ST}_{\mathrm{i}}+\mathrm{S}_{\mathrm{ij}}+\mathrm{H}_{\mathrm{ijk}}+\mathrm{A}_{\mathrm{ijkm}}
$$

where

$\mathrm{i}=1,2, \ldots, \mathrm{a} ; \mathrm{a}$ is the number of sectors

$\mathrm{j}=1,2, \ldots, \mathrm{b}$; $\mathrm{b}$ is the number of samples per sector

$\mathbf{k}=1,2, \ldots, \mathrm{c} ; \mathrm{c}$ is the number of homogenized aliquots prepared from each sample $\mathbf{m}=1,2, \ldots, \mathrm{n} ; \mathbf{n}$ is the number of analyses per aliquot.

In Equation 4.2

$\mu$
$\mathrm{ST}_{\mathrm{i}}=\quad$ the true unknown mean concentration of the analyte being estimated
$\mathrm{S}_{\mathrm{ij}}=$ the effect of taking samples within the $\mathrm{i} t h$ sector
$\mathrm{H}_{\mathrm{ijk}}=$ the effect of taking the $\mathrm{j} t h$ sample within the $\mathrm{i} t h$ sector
$\mathrm{A}_{\mathrm{ijkm} \mathrm{m}}=$ the effect of the $\mathrm{k} t h$ aliquot from the $\mathrm{j} t h$ sample within the $\mathrm{i} t h$ sector,


The response $\mathrm{y}_{\mathrm{ijkm}}$ is the observed concentration of an analyte from the $\mathrm{m} t h$ analysis on the $\mathrm{k} t h$ aliquot from the jth sample within the ith sector. This model applies to each analyte within the waste. To fit this model to the data, a total of abcn observations or chemical analyses are required.

The four factors in the statistical model (sector, samples, aliquots and laboratory analyses) are assumed to be random variables that are uncorrelated and normally distributed with means zero and variances $\sigma^{2}(\mathrm{ST}), \sigma^{2}(\mathrm{~S}), \sigma^{2}(\mathrm{H})$ and $\sigma^{2}(\mathrm{~A})$ respectively. It is the four variances $\left(\sigma^{2}(\mathrm{ST})\right.$, $\sigma^{2}(S), \sigma^{2}(H)$ and $\left.\sigma^{2}(A)\right)$, not the individual effects (ST, S, H, and A), that are of interest.

These four variances are used to determine how well the mean concentration of an analyte has been estimated and how the number of observations can be reduced. These variances have the following interpretations.

- $\quad \sigma^{2}(\mathrm{ST})$ denotes the variability between sectors. It is estimated from the observed differences in average analyte concentration between the sectors. It is a "global" or between sectors measure of waste heterogeneity.

- $\quad \sigma^{2}(S)$ denotes the variance between samples. It is estimated from differences among average concentrations between samples within the same sector. It is a "local" or within sector measure of waste heterogeneity.

- $\quad \sigma^{2}(\mathrm{H})$ denotes the variance between aliquots from the same sample. It is estimated from differences among average values from aliquots taken from the samples. If samples are homogenized, it is a measure of homogeneity of prepared sample. If it is "large," the samples are not well mixed or prepared. The magnitude of this variance can be controlled in the laboratory by taking steps to ensure proper sample mixing or preparation. Alternatively, if the samples are not homogenized, this variance is a local measure of waste heterogeneity.

- $\quad \sigma^{2}(\mathrm{~A})$ denotes the analytical measurement variability. It is estimated from differences between analytical measurements on the same aliquot. This is a measure of agreement between replicated chemical analyses on the same material. This variance is the reference value for statistical comparisons.

The variance components $\sigma^{2}(\mathrm{ST})$ and $\sigma^{2}(\mathrm{~S})$ are measures of spatial variability associated with the waste. The magnitude of these variances cannot be controlled. If the sectors are formed from similar materials then $\sigma^{2}(\mathrm{~S})$ should be small as compared to $\sigma^{2}(\mathrm{ST})$. The variance $\sigma^{2}(\mathrm{~A})$ is associated with laboratory measurements and its magnitude can be controlled. The variance $\sigma^{2}(H)$ can be a measure of local spatial variability or of the laboratories ability to homogenize samples. 
The ANOVA associated with the model can be used to test whether or not there are differences in analyte concentrations within the sectors, between the sectors and if the homogenization is adequate; i.e. that $\sigma^{2}(\mathrm{ST}), \sigma^{2}(\mathrm{~S})$, and $\sigma^{2}(\mathrm{H})$ cannot be distinguished from zero. The ANOVA can also be used to determine which terms in Equation 4.2 are significant and if simpler models can be used to describe the data. The reference value for the statistical tests is the analytical measurement variance $\sigma^{2}(\mathrm{~A})$.

The details associated with the ANOVA (for the balanced case), are given in Appendix A of Jensen and Liebetrau (1988). That appendix also outlines several uses of the variance components that are not given here.

Usually, the ANOVA is unbalanced. It is unbalanced if the range of the subscripts $a, b, c$, and $n$ are functions of $\mathrm{i}, \mathrm{j}$, and $\mathrm{k}$; i.e., the ranges are $a, b, c_{i j}$, and $n_{i j k}$. If the ANOVA is unbalanced, the computations are complicated. To fit the ANOVA models to the data, restricted maximum likelihood estimation (REML) techniques will be used. REML methods will be used to obtain estimates of means, the variance of the mean, and the variance components. These techniques are discussed in Harville (1977).

The statistical program S-Plus ${ }^{5}$ (StatSci 1995) will be used to fit the ANOVA models to the data. S-Plus will be used to obtain the REML estimates of $\mu$, the variance components $\left(\sigma^{2}(\mathrm{ST}), \sigma^{2}(\mathrm{~S}), \sigma^{2}(\mathrm{H})\right.$ and $\left.\sigma^{2}(\mathrm{~A})\right)$ and the variance of the mean. The program will also be used to determine which terms in the ANOVA model (Equation 4.2) are significant and if simpler models can also be used to describe the data.

An additional term, denoting waste compartment, can be incorporated into Equation 4.2. The ANOVA results from the larger model can be used to test whether or not the spatial variabilities, and mean concentrations, between waste compartments are significantly different from each other. The results of the statistical tests can be used to determine whether or not the data from the different compartments can be combined.

\subsection{VARIANCE OF THE MEAN}

The total variance of a single observation $\mathrm{y}_{\mathrm{j} \mathrm{j} \mathrm{km}}$ from Equation 4.2 can be decomposed into four individual components

$$
\sigma^{2}\left(y_{i j k m}\right)=\sigma^{2}(S T)+\sigma^{2}(S)+\sigma^{2}(H)+\sigma^{2}(A)
$$

In the balanced case, the sample mean is an unbiased estimate of the mean concentration $\mu$. (The sample mean $\overline{\mathrm{y}}$ has the same interpretation as the $\overline{\mathrm{c}}$ introduced in Section 3.0.) The

${ }^{5} \mathrm{~S}$-Plus is a registered trademark of Mathsoft, Inc. 
variance of the sample mean of the total of abcn observations (see Chapter 13 of Snedecor and Cochran 1980) is

$$
\sigma^{2}(\bar{y})=\frac{\sigma^{2}(\mathrm{ST})}{a}+\frac{\sigma^{2}(\mathrm{~S})}{a b}+\frac{\sigma^{2}(\mathrm{H})}{\mathrm{abc}}+\frac{\sigma^{2}(\mathrm{~A})}{\mathrm{abcn}} .
$$

In Equation 4.3 the individual variance components are weighted equally, but in Equation 4.4 the variance components are weighted inversely proportional to the numbers of observations a, $\mathbf{b}, \mathrm{c}$, and $\mathbf{n}$. This weighting can be used to choose the number of observations $\mathrm{a}, \mathrm{b}$, $\mathrm{c}$, and $\mathrm{n}$ to control the contribution of the individual variance components to the variance of the sample mean.

Based on statistical analyses of tank characterization data, the magnitude of the variance of the mean is usually controlled by the spatial variability $\sigma^{2}(\mathrm{ST})$ and $\sigma^{2}(\mathrm{~S})$. The variance components associated with laboratory measurements $\left(\sigma^{2}(\mathrm{H})\right.$ and $\left.\sigma^{2}(\mathrm{~A})\right)$ have large denominators, and their contribution to the variance of the mean are usually negligible. In addition, the magnitude of $\sigma^{2}(\mathrm{~A})$, and perhaps of $\sigma^{2}(\mathrm{H})$, can be controlled in the laboratory. The magnitude of the spatial variabilities $\left(\sigma^{2}(\mathrm{ST})\right.$ and $\left.\sigma^{2}(\mathrm{~S})\right)$ cannot be controlled.

The lower and upper limits (LL(95\%) and UL(95\%)) to the 95 percent confidence interval on the mean concentration are

$$
\begin{aligned}
& \operatorname{LL}(95 \%)=\bar{y}-t_{(a-1,0.05)} \sqrt{\sigma^{2}(\bar{y})}, \\
& U L(95 \%)=\vec{y}+t_{(a-1,0.05)} \sqrt{\sigma^{2}(\bar{y})} .
\end{aligned}
$$

In this interval, $\sigma^{2}(\bar{y})$, is the estimate of the variance of $\bar{y}$ and $t_{(\mathrm{a}-1,0.05)}$ is the appropriate quantile, for a two-sided 95 percent confidence interval, from Student's $t$ distribution with $a-1$ degrees of freedom.

The width of the confidence interval is controlled by two factors. The first is the degrees of freedom $a-1$, where $a$ is the number of strata (a quantile from Student's $\mathbf{t}$ distribution, $\mathrm{t}_{(\mathrm{a}-1,0.05)}$, decrease as the degrees of freedom increase). The second factor is the estimated variance of the mean. The magnitude of this variance is usually controlled by the spatial variability and it can be decreased by increasing the number of sectors, $a$, and the number of samples per sector, $b$. 
HNF-SD-WM-TI-799 Rev. 0

This page intentionally left blank. 


\subsection{SPECIFIC SAMPLING PLANS}

Four sampling plans are presented in this section. The plans are based on a stratified random sample, a stratified random sample with composite samples, a random sample, and a random sample with composite samples.

\subsection{STRATIFIED RANDOM SAMPLING PLAN}

The general sampling plan developed in Sections 3.0 and 4.0 is a stratified random sampling plan for characterizing the residual waste in any compartment. The plan consists of four steps. They are

- Divide the compartment into $a$ disjoint strata or sectors,

- Obtain $b$ waste samples within each sector,

- Prepare $c$ aliquots of each sample for analysis,

- Perform $n$ chemical analyses on each aliquot.

This plan requires a total of $a b$ samples and $a b c n$ observations or chemical analyses per analyte. The variance of the mean is

$$
\sigma^{2}(\bar{y})=\frac{\sigma^{2}(\mathrm{ST})}{a}+\frac{\sigma^{2}(\mathrm{~S})}{\mathrm{ab}}+\frac{\sigma^{2}(\mathrm{H})}{\mathrm{abc}}+\frac{\sigma^{2}(\mathrm{~A})}{\mathrm{abcn}} .
$$

The lower and upper limits (LL(95\%) and UL(95\%)) to the 95 percent confidence interval on the mean concentration are

$$
\begin{aligned}
& \operatorname{LL}(95 \%)=\bar{y}-t_{(a-1,0.05)} \times \sqrt{\sigma^{2}(\bar{y})}, \\
& U L(95 \%)=\bar{y}+t_{(a-1,0.05)} \times \sqrt{\sigma^{2}(\bar{y})} .
\end{aligned}
$$

In this interval $\sigma^{2}(\bar{y})$ is the estimate of the variance of $\bar{y}$ and $t_{(\mathrm{a}-1,0.05)}$ is the appropriate quantile, for a two-sided 95 percent confidence interval, from Student's t distribution with $a-1$ degrees of freedom. In this sampling plan, $a$ is the number of strata. 


\subsection{RANDOM SAMPLING PLAN}

An alternative sampling plan is to obtain samples from randomly selected locations within a compartment. The compartment is not divided into strata. This sampling plan consists of three steps. They are

- Obtain $a$ waste samples within the compartment

- Prepare $c$ aliquots of each sample for analysis

- Perform $n$ chemical analyses on each aliquot.

This plan requires a total of $a$ samples and an observations or chemical analyses per analyte. The variance of the sample mean is

$$
\sigma^{2}(\bar{y})=\frac{\sigma^{2}(S)}{a}+\frac{\sigma^{2}(H)}{a c}+\frac{\sigma^{2}(A)}{a c n} .
$$

The variance, $\sigma^{2}(S)$, is the variance between samples within the compartment. The lower and upper limits (LL(95\%) and UL(95\%)) to the 95 percent confidence interval on the mean concentration are

$$
\begin{aligned}
& \operatorname{LL}(95 \%)=\bar{y}-t_{(a-1,0.05)} \times \sqrt{\sigma^{2}(\bar{y})}, \\
& U L(95 \%)=\bar{y}+t_{(a-1,0.05)} \times \sqrt{\sigma^{2}(\bar{y})} .
\end{aligned}
$$

In this interval $\delta^{2}(\bar{y})$ is the estimate of the variance of $\bar{y}$ and $t_{(a-1,0.05)}$ is the appropriate quantile, for a two-sided 95 percent confidence interval, from Student's t distribution with $a-I$ degrees of freedom. In this sampling plan, $a$ is the number of samples.

A random sampling plan can be used to estimate analyte concentrations in each compartment. If the individual compartments are strata then the variance of the mean and confidence interval on the mean for the residual waste in the tank has a form similar to Equations 5.1 and 5.2.

\subsection{COMPOSITE SAMPLES}

Alternative sampling plans are identical to the two described above but are based on the use of composite samples.

In the stratified random sampling plan, let each of the $b$ samples per sector be a composite sample formed from $d$ randomly selected samples within each sector. There are a total of add samples and $a b c n$ observations or chemical analyses per analyte. The variance of the mean 
and the confidence interval on the mean are given in Equations 5.1 and 5.2. The number, $d$, of individual samples forming each composite sample does not appear.

In the random sampling plan let each of the $a$ samples be a composite sample formed from $d$ randomly selected samples within the compartment. There are a total of ad samples and an observations or chemical analyses per analyte. The variance of the mean and the confidence interval on the mean are given in Equations 5.3 and 5.4. The number, $d$, of individual samples forming each composite sample does not appear.

The number of samples, $d$, used to form each composite sample does not appear in the variance of the mean. The conclusion is that the number of composite samples does not reduce the variance of the mean.

\subsection{COMPARISON OF SAMPLING PLANS}

Table 5-1 lists the number of samples and number of observations required by the four types of sampling plans. For the stratified random sampling plans, $a$ denotes the number of sectors and $b$ is the number of samples per sector. For the random sampling plans, $a$ denotes the number of samples. In addition, $c$ denotes the number of aliquots per sample and $n$ is the number of analyses per aliquot.

Table 5-1. Comparison of sampling plans.

\begin{tabular}{|c|c|c|c|}
\hline Sampling Plan & Hominerof & obserfotions & Varinge of Mern \\
\hline Stratified random sample & $a b$ & abcn & Equation 5.1 \\
\hline $\begin{array}{l}\text { Stratified random sample } \\
\text { with composite samples }\end{array}$ & add & abcn & Equation 5.1 \\
\hline Random sample & a & an & Equation 5.3 \\
\hline $\begin{array}{l}\text { Random sample with } \\
\text { composite samples }\end{array}$ & ad & an & Equation 5.3 \\
\hline
\end{tabular}


HNF-SD-WM-TI-799 Rev. 0

This page intentionally left blank. 


\subsection{SAMPLING PLAN FOR THE WASTE PLUME}

Statistical sampling plans used to locating the boundary and to characterize the waste within an underground plume are based on methods originally developed by the mining industry. Such plans are described in detail by Cressie (1993).

The sampling plan is a grid on the surface above the waste plume. Nodes of the grid are defined by an $(\mathrm{X}, \mathrm{Y})$ coordinate system. At each node of the sampling grid, soil samples are obtained from multiple depths in the $\mathrm{Z}$ direction. The soil samples are analyzed for the constituents of interest. A three dimensional coordinate system, $(\mathrm{X}, \mathrm{Y}, \mathrm{Z})$, is used to identify analyte concentrations.

Statistical techniques known as "Kriging" are used to obtain estimates of analyte concentrations for any point in the three dimensional $(X, Y, Z)$ coordinate system. From the concentration estimates, the boundary of the waste plume can be determined. Kriging methods can also be used to obtain mean analyte concentrations and a confidence intervals on the mean for the volume in the waste plume.

The Kriging methods are presented in Cressie (1993). Software used to analyze this type of spatial data (Kriging methods) have been developed using the statistics software package S-Plus (StatSci 1995). The software, along with examples, are described in the text by Enables and Ripley (1994). 
HNF-SD-WM-TI-799 Rev. 0

This page intentionally left blank. 


\subsection{REFERENCES}

Cressie, N. A. C., 1993, Statistics for Spatial Data, John Wiley \& Sons, Inc.

Jensen, L., A. M. Liebetrau, 1988, Statistical Techniques of Characterizing Single-Shell Tank Wastes, WHC-SA-0348-FP, Westinghouse Hanford Company, Richland, Washington.

Harville, D. A., 1977, Maximum likelihood approaches to variance component estimation and to related problems, Journal of the American Statistical Association, 72:320-340.

Snedecor, W. G. and W. G. Cochran, 1980, Statistical Methods for Research Workers, Th Edition, Iowa State University Press.

StatSci, 1995, S-Plus Guide to Statistical and Mathematical Analysis, Version 3.3, StatSci Division of MathSoft, Inc., Seattle, Washington.

Enables, W. N. and B. D. Ripley, 1994, Modern Applied Statistics with S-Plus, Springer-Verlag, New York, Inc. 
HNF-SD-WM-TI-799 Rev. 0

This page intentionally left blank. 
HNF-SD-WM-TI-799 Rev. 0

APPENDIX A

TANK AX-104 SAMPLING AND CHARACTERIZATION MODELS 
HNF-SD-WM-TI-799 Rev. 0

This page intentionally left blank. 


\section{APPENDIX A}

\section{TANK AX-104 SAMPLING AND CHARACTERIZATION MODELS}

This tank waste characterization model is based on Tank 241-AX-104, which is the initial tank to be addressed in the Hanford Tank Initiative (HTI) project. The objective of HTI is to demonstrate a process to mitigate and close a Hanford high-level waste underground storage tank.

\section{A.1 TANK CLOSURE CHARACTERIZATION NEEDS}

A critical part of the mitigation and closure process is the characterization of the tank waste. The volume of waste remaining in the tank (assuming retrieval operations have been completed) and the concentration of species within this waste residue are specific concerns in determining the acceptability for closure.

The objective of waste characterization is to collect sufficient data to estimate the volume of residual waste and the concentration of each critical waste species. Post-retrieval sampling and analysis data is needed to determine if a tank may be safely closed. As specified in Tri-Party Agreement Milestone M-45-00, one part of the closure criteria is that no more than 360 cubic feet $(10.2 \mathrm{~kL})$ of waste, or the limit of retrieval technology capability, or whichever is less, can be left in a 75 feet diameter SST (WHC-SD-WM-TP-243, Rev. 2 Draft, 1996). The current Closure Work Plan strategy (DOE/RL-89-16, Rev. 1, May 1996) also requires that sufficient information, adequate to assess health and safety risks that are affected by the nature and extent of residual waste/contamination and the effectiveness of closure systems in isolating the contamination from the environment, are needed.

\section{A.2 AX-104 TANK DESIGN AND OPERATIONAL PARAMETERS}

Table A-1 contains a list of the major (as-designed) dimensions and volumes for tank AX-104. The tank was designed with a flat bottom with several channels in the concrete under the steel bottom to duct away any leakage to a detection sump. The tank dome is curved and provides support for approximately six feet of overburden. 
Table A-1. Tank 241-AX-104 Tank Internal Dimensions.

\begin{tabular}{|l|c|}
\hline \multicolumn{1}{|c|}{ Tamk larameter. } & Dimension".2 \\
\hline Diameter (inside) & $75 \mathrm{ft}$ \\
\hline Wall Height (to Dome interface) & $32.5 \mathrm{ft}$ \\
\hline Wall Support Bracket: & $5 \mathrm{in}$ \\
Width & $3.5 \mathrm{in}$ \\
Height & $43.5 \mathrm{ft}$ \\
\hline Dome to Floor (tank center) & $1,000,000$ gal \\
\hline Nominal Tank Capacity & $2750 \mathrm{gal} / \mathrm{in}$. \\
\hline Volume/Height Ratio & \\
\hline
\end{tabular}

Notes:

\author{
Dimensions obtained or estimated from drawings $\mathrm{H}-2-44562, \mathrm{H}-2-73382$, and \\ $\mathrm{H}-2-44676$. \\ ${ }^{2}$ Brevick et al. 1994, Historical Tank Content Estimate for the Northeast Quadrant of \\ the Hanford 200 East Area, WHC-SD-WM-ER-349, Westinghouse Hanford \\ Company, Richland, Washington.
}

The AX farm tanks were designed to store the PUREX and B Plant self concentrating (boiling) aging waste. The air lift circulators (ALCs) and the active forced air ventilation system maintained the waste within a reasonable temperature range. The historical records indicate that it was necessary to add water to replace lost moisture. The additional moisture was needed to maintain thermal conductivity and control the tank's temperature. Mercier et al. 1984, indicate that for a short time period the average waste thermocouple temperature for AX-104 was over $325^{\circ} \mathrm{F}$ in the second quarter of 1970 . This high temperature could have had an adverse affect on the tank structure. However, the record also shows that AX-104's waste inventory was maintained at a level between 800,000 to $1,000,000$ gallons. This volume would maintain pressure on the tank bottom and sidewalls that may have opposed any thermally induced warping or buckling.

The in-tank video and still images of AX-104 show that it currently contains hardware items extending from the dome down to the bottom of the tank. These include risers with dry wells, thermocouple trees, pumps, sluicing hardware and 22 ALCs which were installed when the tank was built. All of the structures which extended below the wall/dome interface would have been in contact with the waste and may have a large waste inventory on their surfaces. The ALCs may have produced airborne materials (aerosols) that may have collected on the dome and riser surfaces in the air space above the waste. 


\section{A.3 AX-104 TANK CHARACTERIZATION MODEL}

Based on video and still images of the interior of AX-104, a tank model, used to evaluate characterization approaches, divides the tank into four areas:

1. Tank Bottom:

This is the horizontal and sidewall interface area of the 75 feet diameter tank bottom

2. Tank Sidewall:

a. Vertical Flat Areas

This is the 32.5 feet vertical sidewall of the tank interior.

b. Sidewall $5 \times 3 \frac{1}{2}$ inch support member

The tank sidewall contains 11 ribs, spaced at 3 feet intervals. These ribs are oriented so that 5 inches extends out into the tank and $3 \frac{1}{2}$ inches hangs down from the end.

3. Tank Dome:

This is the interior surface of the tank dome that covers the headspace.

4. In-Tank Hardware (ALCs, dry wells, etc.):

There are 22, "as-built" pipe structures through which compressed air was pumped. The air stirred and extracted heat from the waste. There is other piping and hardware also in the tank risers. The ALCs have an exterior and an interior surface that may contain residual waste.

The volume and concentration of analytes on each of these four surface area needs to be addressed.

A detailed discussion of the waste materials that may be adhering to the various surfaces in tank 241-AX-104, is contained in the draft version of WHC-SD-TWR-ER-001, Rev A, 1996, Residual Waste Estimates for AX-104 Tank Closure, Numatec Hanford Corporation, Richland, Washington. 


\section{A.4 AX-104 TANK BOTTOM}

The AX-104 in-tank video and still images indicate that there may be a large volume of waste on the bottom of the tank (WHC-SD-TWR-ER-001, Draft). Figure 1 shows a waste depth contour map developed from visual interpretation of video and still camera images taken through risers R-3A and R-9A (WHC-SD-TWR-ER-001, Rev. A, Draft, 1996). The waste depth was mapped in contours, representing 2 inch depth increments over a 2 to 14 inch depth range. A summary of the waste in the contours, shown in Table A-2, indicates that $80 \%$ of the tank bottom area may have a waste depth greater than 9-10 inches. However, the volume estimate shows that about $40 \%$ of the tank bottom has 10 inches of waste. There may be areas that have waste greater than 14 inches deep.

Table A-2. Tank 241-AX-104 Approximate Bottom Waste Depth Summary from Visually Derived Depth

Contour Map', preliminary results

\begin{tabular}{|c|c|c|c|c|}
\hline 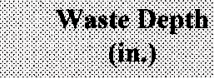 & $\left(t^{3}\right)$ & $\% \%$ & (ollame & \%olotar \\
\hline 14 ( $>13$ in.) & 1021 & $24 \%$ & 1192 & $27 \%$ \\
\hline $12(11-13$ in.) & 352 & $8 \%$ & 352 & $8 \%$ \\
\hline 10 (9-13 in.) & 2017 & $48 \%$ & 1682 & $38 \%$ \\
\hline 8 (7-9 in.) & 429 & $10 \%$ & 287 & $7 \%$ \\
\hline 6 (5-7 in.) & 49 & $1 \%$ & 24 & $<1 \%$ \\
\hline $4^{(2)}(<5$ in. $)$ & $343^{(3)}$ & $8 \%$ & 857 & $20 \%$ \\
\hline Totals: & 4211 & & 4395 & \\
\hline
\end{tabular}

Notes:

${ }^{1}$ Data from bottom contour map in WHC-SD-TWR-ER-001, Draft.

${ }^{2}$ Area under the $22 \mathrm{AX}-104$ air lift circulators.

${ }^{3}$ The $205 \mathrm{ft}^{3}$ area covered by pumps and other equipment sitting on the tank bottom was not included in this area.

The AX-104 in-tank video and still images show that the surface of the bottom waste may not be homogeneous in color or texture. The areas under each ALC, under the two sluicers (R-1A and R-1B) and under the sluicing pump (R-14) appear to be dark grey with a smooth surface. Other waste areas on the bottom appear to have a rough surface with white areas. Dark grey areas may be sub-layers under brightly colored layers. The grey colored waste may be insoluble precipates which were laid down by the "shifting" action of the ALC's. The content of this grey colored waste may be different from the waste in the overlaying layers. 
Figure 1. Tank AX-104 Bottom Waste Depth Map, From WHC-SD-TWR-ER-001, Rev. A,Draft. Depth Legend: Black-14", Dark Gray-12", Gray-10", Light Gray-8", Small Areas Within Dark Gray-6", White-4".

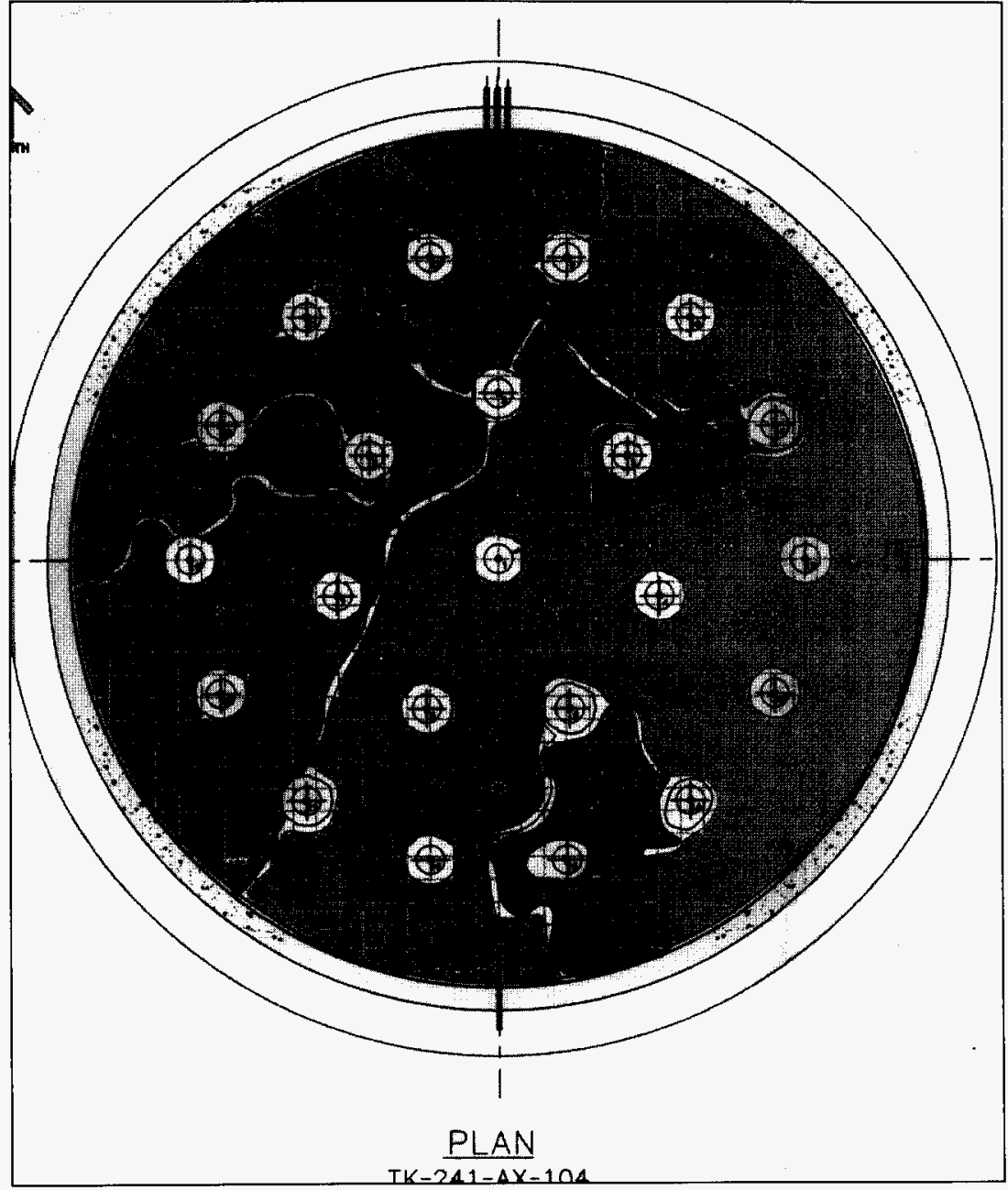




\section{A.5 TANK BOTTOM WASTE SAMPLING}

The topography of the waste surface appears to be rough with lumps and clumps of waste scattered around. The tank bottom under the waste may be relatively smooth. However, the high temperature in AX-104 (in the second quarter of 1970, an average thermocouple temperature for AX-104 was over $300^{\circ} \mathrm{F}$ ) could have adversely affected the flatness of the tank bottom (Mercier et al. 1984), although as previously stated, the high waste level in the tank may have countered the tendency to buckle.

One approach to bottom waste characterization is to use a two-part process. First a stereo camera would be used to establish an accurate topography map of the surface of the tank bottom waste. This would be a relatively high grid density topography mapping, with each mapped point indexed to an $(x, y, z)$ reference point. The second step would be to obtain a waste depth map with a remote vehicle deployed over the tank bottom. This would not require the same grid density as the waste surface topography map requires, since the bottom is expected to be much smoother than the surface of the waste. The position of the vehicle would be tracked to provide $\mathrm{x}, \mathrm{y}$ coordinates for each sampled point. It is assumed that a camera or a position-sensing system would be used to obtain the position data. The waste depth map would be combined with the surface topography map to provide an estimate of the waste volume on the tank bottom.

\section{A.6 BOTTOM SPECIES SAMPLING}

The current images of the waste on the bottom of AX-104 indicate that the residual waste may have layers with different species. Several visual features support this statement. A complicating factor to obtaining samples is that waste layering does not appear to be uniform over the tank floor. Waste samples from the surface would not provide adequate data. Full depth sampling over the tank bottom area will be needed. A remotely deployed vehicle with sampling and sample handling capabilities may be needed.

Prior to deployment of a remote sampling vehicle, it is recommended that a remote arm, such as the LUDA, be used to obtain several waste samples from the bottom surface. These would be used to estimate the degree of homogeneity within the waste. The physical properties data would also be used to design the sampling hardware. 
Figure 2A. Tank AX-104 Bottom Waste Depth Contours From 8" to 14". Depth Areas Based On Approximations To The Depth Contour Map In Figure 1.

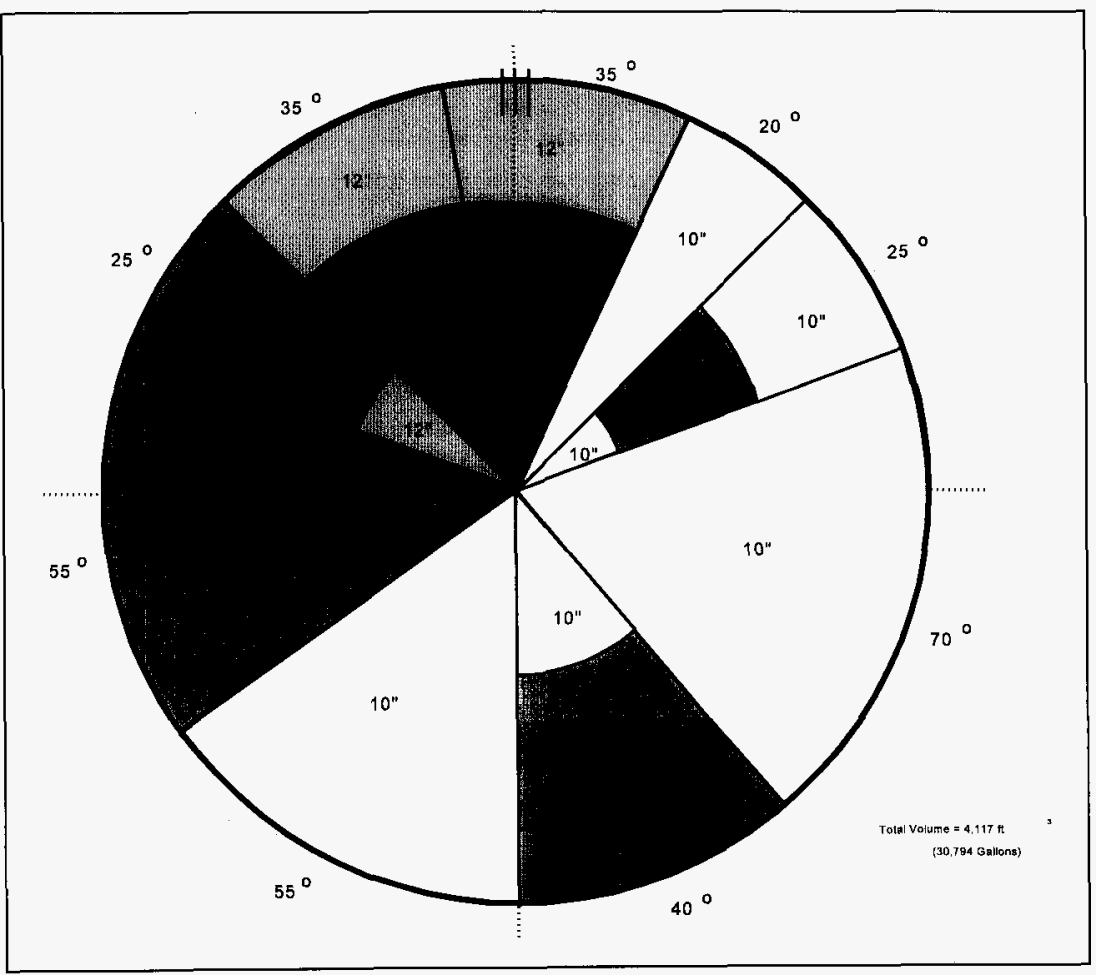


Figure 2B. Tank AX-104 Bottom Waste Depth Example Model (see Figure 2A), With Estimated Waste Tank Area, Waste Depth and Volume

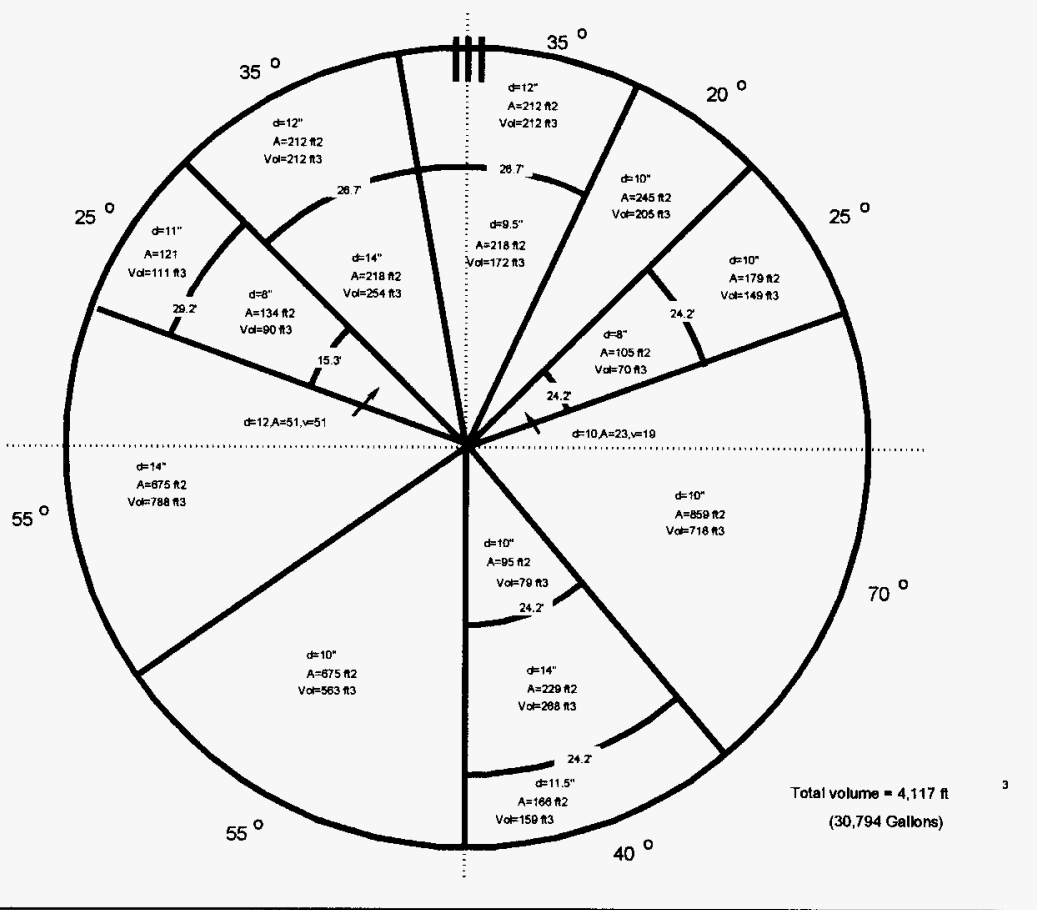




\section{A.7 SAMPLING EXAMPLE FOR AX-104 TANK BOTTOM}

Based on the limited topography and depth sampling data, a bottom waste depth model was prepared as shown in Figure 2A and 2B. This model could have been the results of limited sampling across the tank bottom with depth data extrapolated between sampling points. The cross-hatched areas in Figure $2 \mathrm{~A}$ represent 7 depth contours covering an 8 to 14 in. range.

Figure 2B includes depth, area, and volume details for each mapped sector. Table A-3 summarizes the mapped waste parameters for each depth contour shown in Figures $2 \mathrm{~A}$ and $2 \mathrm{~B}$ (similar to Table A-2). The areas in Figures $2 \mathrm{~A}$ and $2 \mathrm{~B}$ were selected using the visual data that shows waste features that were produced in the final sluicing process. The shallow regions under the ALCs and other Riser hardware were omitted, with waste depth assumed to be the same as the surrounding surface area. In reality, the sluicing action is suspected to have impacted both waste depth and content as the velocity of waste and water flow away from a sluicing nozzle is expected to have changed as a function of distance from the sluicing nozzles.

Table A-3. AX-104 Bottom Waste Depth Summary from Volume Estimates, Approximate Values

\begin{tabular}{|c|c|c|c|c|}
\hline $\begin{array}{l}\text { Waste Depth } \\
(\mathrm{ji})\end{array}$ & Area & $\begin{array}{l}9 \%, 019 \\
\text { lontrong }\end{array}$ & $\begin{array}{l}\text { Yolume } \\
\text { (fi) }\end{array}$ & $\begin{array}{l}\% \text { Total } \\
\text { Volume }\end{array}$ \\
\hline 14 & 1120 & $25 \%$ & 1307 & $32 \%$ \\
\hline 12 & 475 & $11 \%$ & 475 & $11 \%$ \\
\hline 11.5 & 170 & $4 \%$ & 163 & $4 \%$ \\
\hline 11 & 120 & $3 \%$ & 110 & $3 \%$ \\
\hline 10 & 2070 & $47 \%$ & 1725 & $42 \%$ \\
\hline 9.5 & 220 & $5 \%$ & 174 & $4 \%$ \\
\hline 8 & 240 & $5 \%$ & 160 & $4 \%$ \\
\hline 6 & 0 & 0 & 0 & 0 \\
\hline 4 & 0 & 0 & 0 & 0 \\
\hline Totals: & 4415 & & 4114 & \\
\hline
\end{tabular}

A comparison of this Table data (Figure 2A and 2B mapping model) with the data in Table A-2 (data from the Figure 1 map) indicates:

1. The Figure $2 \mathrm{~A}$ and $2 \mathrm{~B}$ model over-predicts the waste volume by a small amount ( 4415 cubic feet versus 4394 cubic feet). This does not include variability from 
the measurement systems used to gather the waste depth and surface topography data.

2. The Figure $2 \mathrm{~A}$ and $2 \mathrm{~B}$ model shows a minimum waste depth of 8 inches verses the 4 inch limit indicated in Figure 1.

\section{A.8 AX-104 TANK DOME AREA}

According to process records, no portion of the AX-104 tank dome was ever in direct contact with the stored waste. However, the dome would have been exposed to airborne aerosols and moisture. Consequently, waste may be on the interior surface of the dome. This transport of wastes to the dome is supported by the tanks suspected leak location. The location is believed to be in the vent header that exhausts air from the tank (Brevick). The vent system enters the tank through the dome, and the exhaust system piping is above the tank.

The video and still images of the tank dome surface (taken from Riser 3-A and 9-A) indicate that most of the dome surface area may be covered with a white residue. However, the whiteness is not uniform over the whole dome surface as illustrated by Figure 3 . This white residue may be tank waste plus any material that may have been leached from the concrete.

The waste adhering to the dome interior surface may be fairly homogeneous. This is based on the visual consistency of the waste colorations and the consistency in color may be related to species homogeneity. Several samples of the material from different locations on the interior surface of the dome will be required. These samples could be obtained with the LUDA.

\section{A.9 TANK SIDEWALL AREA}

The large volume of waste that was maintained in tank AX-104 (800,000-1,000,000 gal) would have kept at least $80 \%$ of the sidewall area immersed in tank wastes for most of AX-104s operational lifetime. During sluicing operations, the sidewalls would have been exposed to aerosols and splash from the nozzles.

In-tank images indicate that the flat areas of the tank sidewall appear to have a rather uniform color. This color appears to be darker than the color of waste on the surface of near-by ALCs. This would indicate that the walls may not have the same waste as on the ALC hardware. In fact, the dark, rust coloring of the tank walls may indicate that there is little waste adhering to the vertical surface of the sidewall.

Construction details of AX-104 show that the tank sidewall (32.5 feet high) contains 11 circumferential support brackets $(5 \times 3 \mathrm{1} / 2$ inches) located on vertical intervals three feet apart. The images of the tank interior show that the horizontal surface of these brackets ( 5 inch dimension) and the dome-wall interface (ledge-like feature) both appear to have clumps of waste residue. 
Figure 3. Image of AX-104 Tank Dome Surface from Riser 3-A, Looking North.

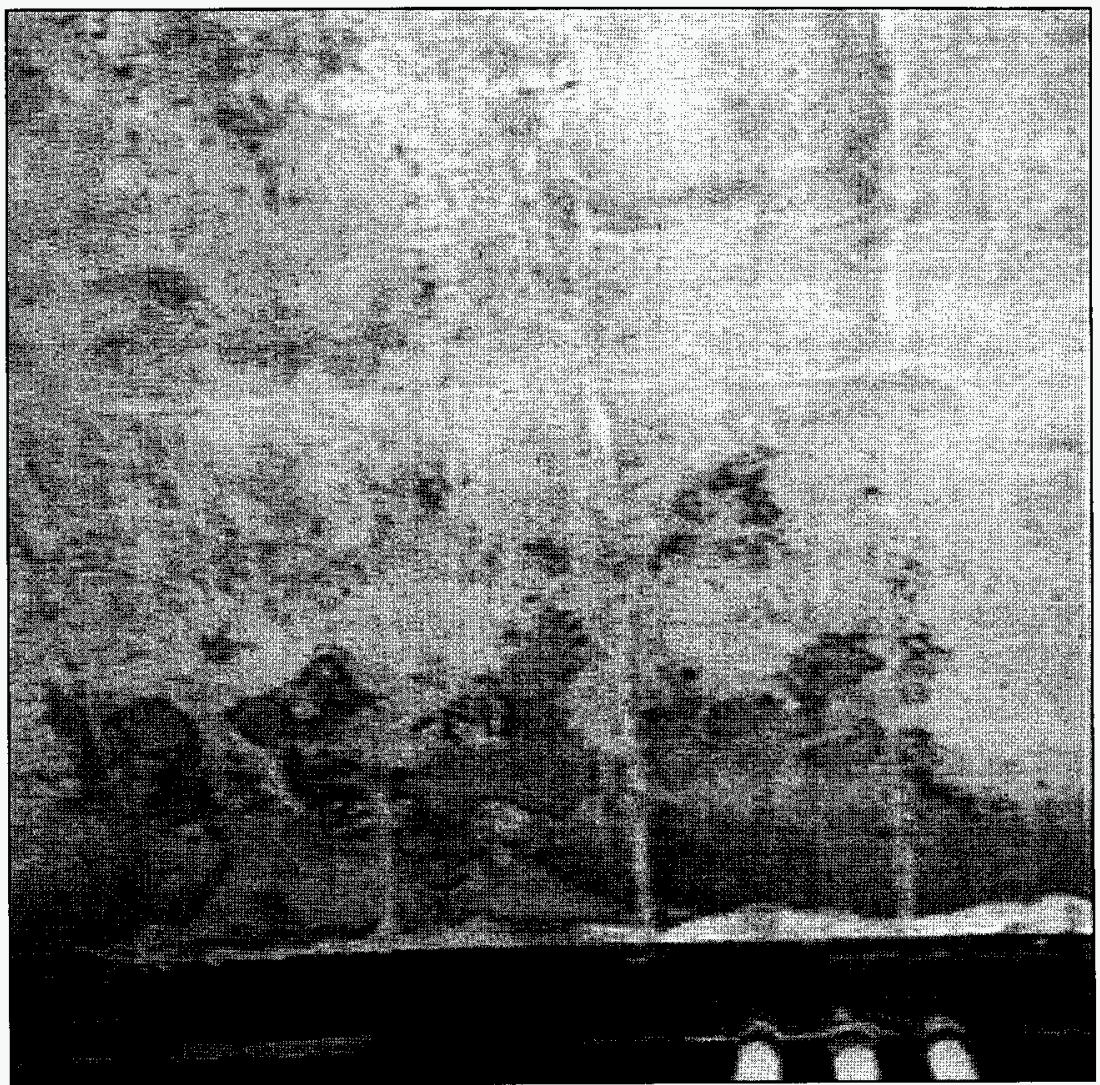


All of the waste residue (on the wall, brackets, and at the interface) appears to be light colored. This waste does not appear to have layers.

\section{A.10 TANK WALL WASTE SAMPLING MODEL}

To characterize the waste on AX-104's walls, samples are needed from both the wall vertical areas and from the $5 \times 3 \frac{1 / 2}{2}$ inch brackets. The areas near the sluicing nozzles (R-1B and R-1A) may have been splashed when the tank was sluiced. Areas further away, such as adjacent to the sluicing pit (R-14) containing the sluicer pump, may not have been splashed. These area may contain different types of waste.

One approach to sampling would be to obtain samples of waste on the wall and brackets from several locations. At each location, samples would be taken up the side of the wall. A scratch sampling method would provide sample material as well as a means to visually assess waste volume. Waste samples should also be taken from the lowest and highest $5 \times 3 \mathrm{l} / 2$ inch bracket. A visual mapping of the waste on the brackets around the tank circumference would provide data for estimating waste volumes

Samples should also be obtained from waste on the under and hidden side of the $5 \times 31 / 2$ inch bracket. These samples are needed to justify assumptions regarding waste volume estimates.

\section{A.11 TANK WALL WASTE VOLUME ESTIMATES}

Table A-4 shows estimated waste volumes for the vertical surface area of the tank sidewall over a range of assumed potential waste depths. The estimates include the outer exposed 3 inch surface of the $5 \times 3 \frac{1}{2}$ inch bracket. This table shows that even with fairly shallow waste depths, the sidewall area could hold a large volume of waste. If the inner/under surfaces of the $5 \times 31 / 2$ inch bracket is included, the total sidewall area increases about $17 \%$ as shown in Table A-4. Since this bracket was submersed in the tank waste, it may contain waste residue on all its surfaces.

\section{A.12 IN TANK HARDWARE}

Tank AX-104 currently contains in-tank hardware such as ALCs, dry wells, sluicing piping, pumps, and thermocouples. The total surface area of this hardware may be large. The surfaces of ALCs, and the other in-tank hardware such as the transfer and submersible pump hardware, dry wells, sluicers, and thermocouple trees were included in waste residue estimates made in WHC-SD-TWR-ER-001, Draft. The waste residue on the in-tank hardware (does not include the ALCs which are considered separately) near or touching the tank bottom will be part of the bottom waste inventory. 
Table A-4. Tank Sidewall Waste Volumes for a 1/16 to 1 inch Range of Waste Depth

\begin{tabular}{|c|c|c|}
\hline 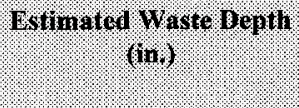 & 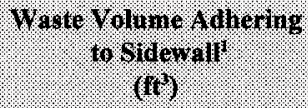 & 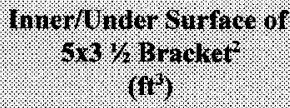 \\
\hline 1 & 640 & 100 \\
\hline $3 / 4$ & 480 & 70 \\
\hline $5 / 8$ & 400 & 60 \\
\hline $1 / 2$ & 320 & 50 \\
\hline $3 / 8$ & 240 & 35 \\
\hline $1 / 4$ & 160 & 25 \\
\hline $1 / 8$ & 80 & 10 \\
\hline $1 / 16$ & 40 & 6 \\
\hline
\end{tabular}

Notes:

'Includes the 3 inch exposed vertical component of the $5 \times 31 / 2$ inch bracket.

${ }^{2}$ Includes the underside of the 5 inch dimension and the "hidden" side of the $31 / 2$ inch bracket which adds about $17 \%$ more surface area to the sidewall area estimate.

Table A-5 gives estimates of the surface areas in the tank. Table A-6 shows estimated waste volumes for the in-tank hardware based on a range of waste depths. These Tables illustrate the following:

1. Compared to the in tank hardware, the in-tank surface area, where waste residue would be found, is dominated by the dome, bottom, sidewalls, and ALC hardware $(24,910$ square feet, this area excludes the wall brackets).

2. The surface area from the in-tank hardware ( 410 square feet) is less than $2 \%$ of the total tank surface. The dome, bottom, sidewalls, and ALCs provide over $98 \%$ of the surface area. Waste residue could be located in all of these areas.

3. Depending on the waste depth and residue on other tank surface areas, the volume of residue on the in-tank hardware may be small enough to neglect. 
Table A-5. AX-104 In-Tank Surface Areas, Approximate Values.

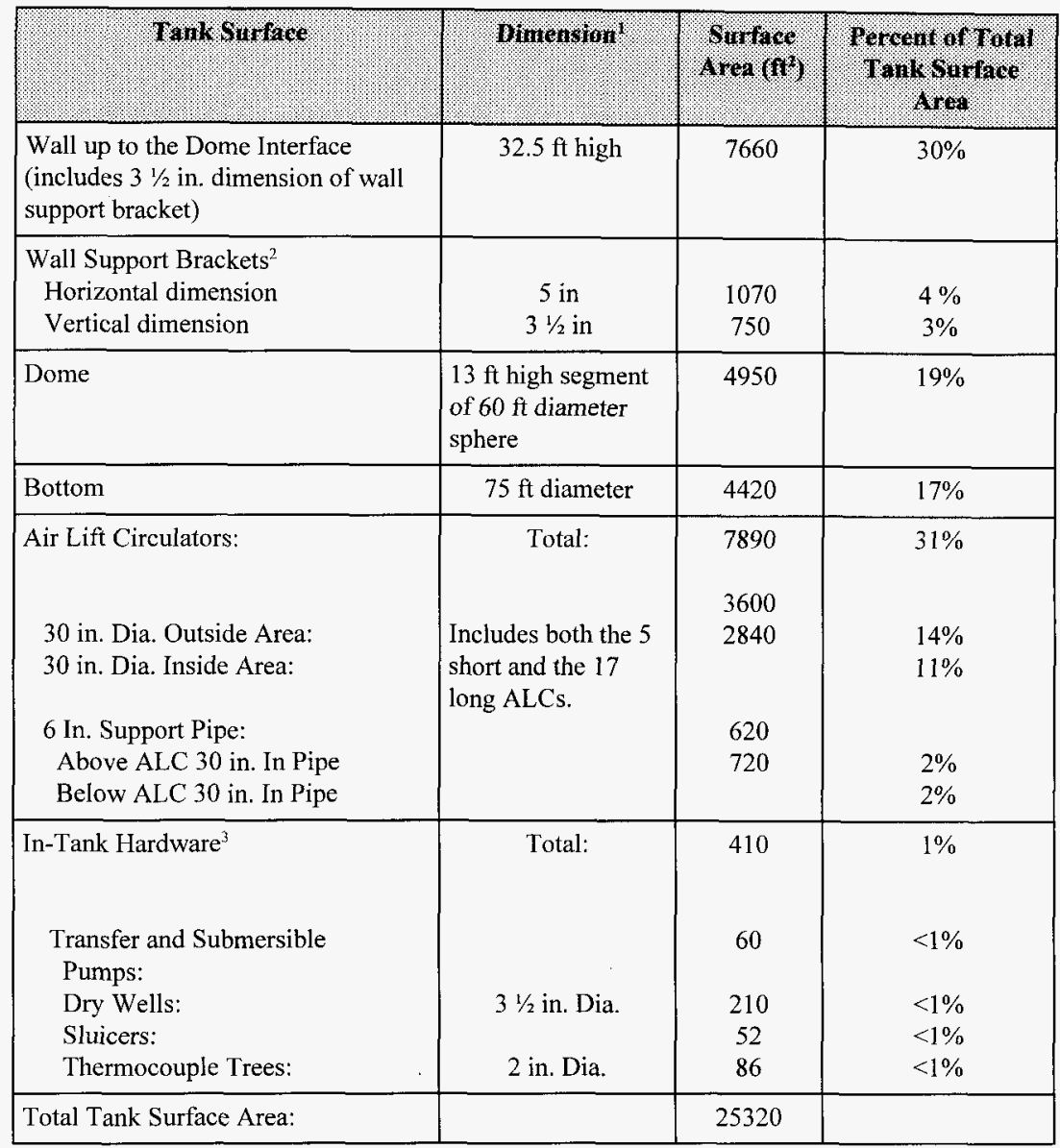

Notes:

${ }^{1}$ Dimensions obtained or estimated from drawings $\mathrm{H}-2-44562, \mathrm{H}-2-73382$, and $\mathrm{H}-2-44676$.

${ }^{2}$ The under-side of the brackets are not included.

${ }^{3}$ Data from WHC-SD-TWR-ER-001, Rev A, Draft, 1996, Residual Waste Estimates for AX-104 Tank Closure, Numatec Hanford Corporation, Richland, Washington. 
Table A-6. In-Tank Hardware Estimated Waste Volume for a Range of Waste Depths.

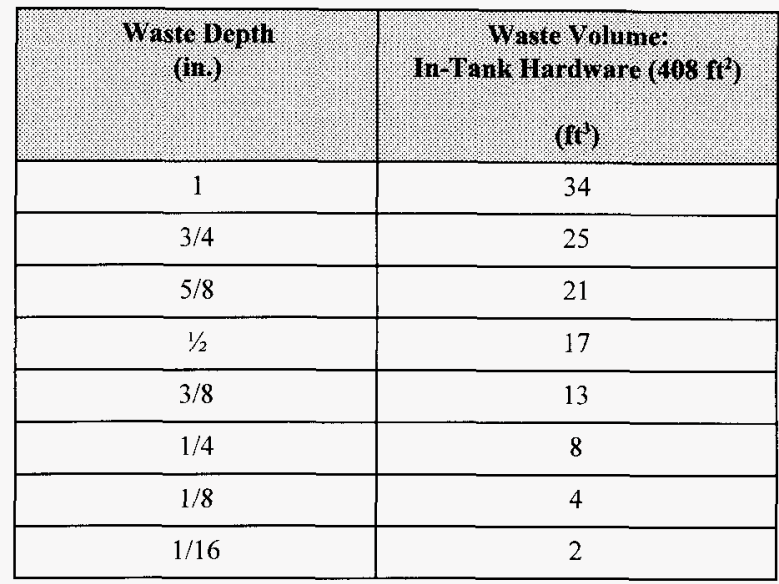

\section{A.13 WASTE SAMPLING ON IN-TANK HARDWARE}

Depth sampling may be needed to establish the depth of the waste on the in-tank hardware. This could be accomplished with a LDUA arm. It may be possible to estimate depth and species content using data from near-by ALC fixtures. 


\section{A.14 APPENDIX A REFERENCES}

Agnew. S. F., R. A Corbin, T. B. Duran, K. A. Jurgensen, T. P. Ortiz, and B. L. Young, 1996, Waste Status and Transaction Record Summary for the Northeast Quadrant of the Hanford 200 Area, WHC-SD-WM-TI-615, Rev. 1, Los Alamos National Laboratory, Los Alamos, New Mexico.

Brevick, C. H., L. A. Gaddis, and W. W. Pickett, 1994, Historical Tank Content Estimate for the Northeast Quadrant of the Hanford 200 East Area, WHC-SD-WM-ER-349, Westinghouse Hanford Company, Richland, Washington.

Hanlon, B. M., 1996, Waste Tank Summary for Month Ending April 30, 1996, WHC-EP-018297, Westinghouse Hanford Company, Richland, Washington.

WHC, 1996, Residual Waste Estimates for AX-104 Tank Closure, WHC-SD-TWR-ER-001, Rev. A, Draft, Numatec Hanford Corporation, Richland, Washington.

Mercier, P. F., C. DeFigh-Price, and M. D. Wonacott, 1984, Summary of the Single-Shell Tank Thermal Histories, RHO-CD-1122, Rockwell Hanford Operations, Richland, Washington.

WHC, 1996, Tank 241-AX-104 Tank Characterization Plan, WHC-SD-WM-TP-243, Rev 2, Draft, Westinghouse Hanford Company, Richland, Washington. 
HNF-SD-WM-TI-799 Rev. 0

APPENDIX B

TANK AX-104 CONSTRUCTION AND OPERATIONAL BACKGROUND SUMMARY 
HNF-SD-WM-TI-799 Rev. 0

This page intentionally left blank. 


\section{APPENDIX B}

\section{TANK AX-104 CONSTRUCTION AND OPERATIONAL BACKGROUND SUMMARY}

Tank 241-AX-104 is part of a four, SST complex that was built in the early 1960's (Brevick 1994). These tanks were designed with a flat bottoms, a diameter of approximately 75 feet and 32.5 feet high sidewall. The storage capacity is about 1,000,000 gallons. The AX tank farm contained no cascade connections.

\section{B.1 AX-104 OPERATIONAL WASTE STORAGE HISTORY}

The AX farm tanks were designed to store the PUREX and B Plant aging waste. This waste boiled or self concentrated from the high inventory of fission products. To maintain reasonable temperatures, tank AX-104 contained 22 air lift circulators and had an active forced air ventilation system to remove tank heat.

The waste storage operations in tank AX-104 were started in 1965 . The tank was initially filled with about 350,000 gal of water (Agnew 1994; Hanlon 1996). PUREX wastes were then periodically added in 25,000 to $130,000 \mathrm{gal}$ increments (Brevick et al. 1994; Agnew 1996). This continued until the 1970s. Periodic transfers were made from AX-104 to tanks such as A-102, $103,-106$ and several other tanks $(250,000$ to 400,000 gal size transfers). From the first quarter of 1973 to the second quarter of 1976, the waste inventory of AX-104 consisted of PUREX sludge supernatant. From the third quarter of 1976 through the first quarter of 1978 the tanks contained evaporator feed.

In 1974, radiation was detected in the dry wells around AX-104 and other AX Tanks. During the third quarter of 1977, AX-104 was sluiced. Since that time, no waste has been transferred into the tank.

Tank AX-104 was declared an assumed leaker in 1978. A waste level adjustment was made and the tank was stabilized. The current waste inventory in AX-104 from historical records is about $27 \mathrm{~kL}$ ( $7,000 \mathrm{gal})$ of residue. This is equivalent to about a $6 \mathrm{~cm}$ ( 2 inches) of waste, as measured from the baseline of the tank bottom.

\section{B.2 TANK AX-104 DESIGN}

The interior of AX-104 currently contains a number of features that will affect tank closure and any characterization or retrieval operations within the tank. These features include dry wells, thermocouple trees, pumps, sluicing hardware and air lift circulators. Risers R-3A and R-9A are currently the only ones that can be used for access. These risers have recently been used for 
video and still photography of the interior. Other risers may be available for characterization activities. However, any hardware in them will have to be removed. Risers that are terminated below grade would not be easily accessible for characterization purposes.

The tank's ALCs are arranged in two concentric circles. A 30 foot diameter inner circle contains $7 \mathrm{ALCs}$, an outer 55 foot diameter circle has 14 ALCS. One ALC is located in the center of the tank. The ALC's were installed during tank construction. An ALC consists of a 30 inch pipe segment that is concentrically mounted around a 6 inch support pipe. All ALC ex-tank piping is below grade which makes these penetrations in the tank unaccessible. The ALCs were constructed with two lengths ( 17 feet and 22 feet) for the 30 inch diameter pipe segment.

The ALCs were mounted on 6 inch pipes which extend through the dome of the tank. The lower end of the 30 inch segment was installed about 2.5 feet above the tank bottom. Each ALC contains a thermowell guide ( $3 / 4$ inch diameter pipe) that extends down from the tank dome through a separate penetration and is attached to the 30 inch diameter ALC segment. The thermowell guides were installed with their lower end about 3 inch above the bottom of the tank. The visibility (or lack of visibility) of the lower end of these thermowells could be used as tank waste level indicators.

Riser R-4 is the tank vent. This vent was connected to an active air circulation system that included condensers and HEPA filters to scavenge water vapor and particulate matter from the exhausted air. The ALCs and the active air ventilation system, are below grade. The ALC system was to control the tank waste temperature by scavenging water vapor from the tank waste. Waste records show that during operations in the early $1970 \mathrm{~s}$, several water additions ( 200,000 gal range) were made to control the temperature.

A more detailed description and list of Risers and in-tank hardware can be found in WHC-SDTWR-ER-001, Rev. A, Draft, 1996, Residual Waste Estimates for AX-104 Tank Closure, Numatec Hanford Corporation, Richland, Washington. 


\section{B.3 APPENDIX B REFERENCES}

Agnew. S. F., R. A Corbin, T. B. Duran, K. A. Jurgensen, T. P. Ortiz, and B. L. Young, 1996, Waste Status and Transaction Record Summary for the Northeast Quadrant of the Hanford 200 Area, WHC-SD-WM-TI-615, Rev. 1, Los Alamos National Laboratory, Los Alamos, New Mexico.

Brevick, C. H., L. A. Gaddis, and W. W. Pickett, 1994, Historical Tank Content Estimate for the Northeast Quadrant of the Hanford 200 East Area, WHC-SD-WM-ER-349, Westinghouse Hanford Company, Richland, Washington.

Hanlon, B. M., 1996, Waste Tank Summary for Month Ending April 30, 1996, WHC-EP-018297, Westinghouse Hanford Company, Richland, Washington.

WHC, 1996, Residual Waste Estimates for AX-104 Tank Closure, WHC-SD-TWR-ER-001, Rev. A, Draft, Numatec Hanford Corporation, Richland, Washington. 
HNF-SD-WM-TI-799 Rev. 0

This page intentionally left blank. 


\begin{tabular}{|c|c|c|c|c|c|}
\hline \multicolumn{6}{|c|}{ DISTRIBUTION SHEET } \\
\hline \multirow{2}{*}{$\begin{array}{l}\text { To } \\
\text { DISTRIBUTION }\end{array}$} & \multirow[t]{2}{*}{ From } & \multirow{2}{*}{\multicolumn{2}{|c|}{ Process Chemistry }} & \multicolumn{2}{|c|}{ Page 1 of 2} \\
\hline & & & & \multicolumn{2}{|l|}{ Date: } \\
\hline \multirow{2}{*}{\multicolumn{4}{|c|}{$\begin{array}{l}\text { Project Title/Work Order } \\
\text { HNF-SD-WM-TI-799, Rev. 0, "Statistical Techniques for } \\
\text { Characterizing Residual Waste in Single-She11 and Double-She11 } \\
\text { Tanks" }\end{array}$}} & \multicolumn{2}{|c|}{ EDT NO.: EDT-613496 } \\
\hline & & & & \multicolumn{2}{|c|}{ ECN NO.: N/A } \\
\hline & Name & MSIN & $\begin{array}{l}\text { Text With } \\
\text { all Attach }\end{array}$ & $\begin{array}{l}\text { Addendum } \\
\text { IA Only }\end{array}$ & $\begin{array}{c}\mathrm{EDT} / \mathrm{ECN} \\
0 \mathrm{n} 3 \mathrm{y}\end{array}$ \\
\hline
\end{tabular}

\section{ONSITE}

\section{U. S. Department of Energy}

J. P. Hanson

P. R. Hernandez

J. F. Thompson, Jr.

C. D. West
K8-50

$57-54$

$57-54$

$57-53$
$X$
$X$
$X$
$X$

Duke Engineering \& Services Hanford, Inc.

W. M. Funderburke

D. F. Iwatate

\section{Informatics Corporation}

S. R. Chapin

W. (Bi11) Root

H6-12

H6- 12

R2-38

H5-68

$x$

$X$ $x$

$x$

Lockheed Martin Hanford Corp.

K. M. Hall

J. W. Hunt

J. G. Kristofzski

R. S. Popie larczyk

R. D. Schreiber

M. L. Sumsion

W. D. Winkelman

Tank Characterization Resource Center

Lockheed Martin Services, Inc.
R2-12

$\mathrm{R} 2-12$

$\mathrm{R} 2-12$

$\mathrm{R} 2-38$

$\mathrm{R} 2-12$

S7-03

$\mathrm{R} 2-12$

$\mathrm{R} 2-12$

A3-88

2

Numatec Hanford Corp.
P. B. Angelier
J. Bourges
M. Cremonini
R. D. Cromar
E. A. Fredenburg
C. E. Jenkins
L. Jensen
J. R. Jewett
L. B. McDonald

S7-45

T6-09

S7-12

R2-12

H6-12

L6-37

R2-12

T6-09

H6-12 


\begin{tabular}{|c|c|c|c|c|c|}
\hline \multicolumn{6}{|c|}{ DISTRIBUTION SHEET } \\
\hline \multirow{2}{*}{$\begin{array}{l}\text { To } \\
\text { DISTRIBUTION }\end{array}$} & \multirow[t]{2}{*}{ From } & \multirow{2}{*}{\multicolumn{2}{|c|}{ Process Chemistry }} & \multicolumn{2}{|c|}{ Page 2 of 2} \\
\hline & & & & Date: & $02 / 03 / 97$ \\
\hline \multirow{2}{*}{\multicolumn{4}{|c|}{$\begin{array}{l}\text { Project Title/Work Order } \\
\text { HNF-SD-WM-TI-799, Rev. 0, "Statistical Techniques for. } \\
\text { Characterizing Residual Waste in Single-She11 and Double-She11 } \\
\text { Tanks" }\end{array}$}} & \multicolumn{2}{|c|}{ EDT N0.: $\quad$ EDT-613496 } \\
\hline & & & & \multicolumn{2}{|c|}{ ECN NO.: $N / A$} \\
\hline & Name & MSIN & $\begin{array}{l}\text { Text With } \\
\text { a1] Attach }\end{array}$ & $\begin{array}{l}\text { Addendum } \\
\text { 1A Only }\end{array}$ & $\begin{array}{c}\mathrm{EDT} / \mathrm{ECN} \\
0 \mathrm{nly}\end{array}$ \\
\hline
\end{tabular}

\section{ONSITE}

Numatec Hanford Corp. - continued

T. E. Rainey

R. E. Raymond

G. L. Troyer

S. R. Wilmarth

$\begin{array}{ll}\text { S7-12 } & X \\ 57-12 & X \\ \text { T6-50 } & X \\ \text { R2 }-12 & X\end{array}$

$\begin{array}{ll}K 5-12 & X \\ K 5-12 & X \\ K 9-91 & X\end{array}$

H5-09

H5- 09

L5-55

$X$
$X$
$X$
$X$

$$
\begin{aligned}
& x \\
& x \\
& x
\end{aligned}
$$$$
\text { X }
$$

Pacific Northwest National Laboratory

D. S. Daly

T. A. Ferryman

A. F. Noonan

\section{SGN Eurisys Services Corp.}

G. A. Barnes

G. N. Boechler

F. R. Reich

\section{OFFSITE}

Glenn Bastiaans

Special Technologies Laboratory

Bechtel Nevada 5520 Ekwill St., Suite B

Santa Barbara, CA 93111

\section{LIMCO}

T. R. Thomas

Lockheed Idaho Technologies Company

P.0. Box 1625, MSIN 3428

765 Lindsey Blvd.

Idaho Fal1s, ID 83415

$x$

